Research article

\title{
Alternative initiation and splicing in dicer gene expression in human breast cells
}

\author{
Charletha V Irvin-Wilson and Gautam Chaudhuri
}

\author{
Division of Cancer Biology, Department of Biomedical Sciences, Meharry Medical College, Nashville, TN 37208, USA \\ Corresponding author: Gautam Chaudhuri, gchaudhuri@mmc.edu
}

Received: 21 Dec 2004 Revisions requested: 7 Mar 2005 Revisions received: 25 Mar 2005 Accepted: 14 Apr 2005 Published: 16 May 2005

Breast Cancer Research 2005, 7:R563-R569 (DOI 10.1186/bcr1043)

This article is online at: http://breast-cancer-research.com/content/7/4/R563

(C) 2005 Irvin-Wilson and Chaudhuri.; licensee BioMed Central Ltd.

This is an Open Access article distributed under the terms of the Creative Commons Attribution License (http://creativecommons.org/licenses/by/ 2.0), which permits unrestricted use, distribution, and reproduction in any medium, provided the original work is properly cited.

\begin{abstract}
Introduction Dicer is a ribonuclease that mediates RNA interference both at the transcriptional and the posttranscriptional levels. Human dicer gene expression is regulated in different tissues. Dicer is responsible for the synthesis of microRNAs and short temporal (st)RNAs that regulate the expression of many genes. Thus, understanding the control of the expression of the dicer gene is essential for the appreciation of double-stranded (ds)RNA-mediated pathways of gene expression. Human dicer mRNA has many upstream open reading frames (uORFs) at the 5'-leader sequences (the nucleotide sequence between the 5 '-end and the start codon of the major ORF), and we studied whether these elements at the 5 '-leader sequences regulate the expression of the dicer gene.

Method We determined the 5'-leader sequences of the dicer mRNAs in human breast cells by 5'-RACE and S1-nuclease protection analysis. We have analyzed the functions of the 5'leader variants by reporter gene expression in vitro and in vivo.

Results We found that the dicer transcripts in human breast cells vary in the sequence of their 5'-leader sequences, and that

alternative promoter selection along with alternative splicing of the 5 '-terminal exons apparently generate these variations. The breast cell has at least two predominant forms of dicer mRNAs, one of which has an additional 110 nucleotides at the 5 '-end. Sequence comparison revealed that the first 80 nucleotides of these mRNA isoforms are encoded by a new exon located approximately $16 \mathrm{~kb}$ upstream of the reported start site. There are 30 extra nucleotides added to the previously reported exon 1. The human breast cells studied predominantly express two 5'leader variants of dicer mRNAs, one with the exons 2 and 3 (long form) and the other without them (short form). By reporter gene expression analysis we found that the exon 2 and 3 sequences at the 5'-leader sequences are greatly inhibitory for the translation of the mRNA into protein.

Conclusion Dicer gene expression in human breast cells is regulated by alternative promoter selection to alter the length and composition of the 5'-leader sequence of its mRNA. Furthermore, alternative splicing of its exon 2 and 3 sequences of their pre-mRNA creates a more translationally competent mRNA in these cells.
\end{abstract}

\section{Introduction}

RNA interference (RNAi), a process of silencing gene expression, involves the generation of short, double-stranded RNA (dsRNA) molecules by an enzyme called dicer, which cleaves RNA duplexes into 21-23 base-pair oligomers [1-8]. These oligomers are called, depending on their end-point functions, small interfering RNAs (siRNA), microRNA (miRNA) or short temporal RNA (stRNA) [9]. These small RNA molecules cause sequence-specific post-transcriptional gene silencing by guiding an endonuclease, the RNAi-induced silencing complex
(RISC), to mRNA $[10,11]$. This ubiquitous process has also been recently reported [12-15] in human cells to induce transcriptional silencing through promoter methylation.

Dicer gene expression is regulated in different tissues in humans [16]. Because dicer catalyzes the biosynthesis of miRNAs and stRNAs that in turn regulate the expression of many genes, it is likely that the expression of the dicer gene itself is a highly regulated process [9-11]. While studying the published 5'-leader sequences of human dicer transcripts we

ATCC = American Type Culture Collection; dsRNA = double-stranded RNA; HME = human mammary epithelial; $\mathrm{kb}=$ kilobases; miRNA = microRNA; $\mathrm{nt}=$ nucleotide; $\mathrm{PCR}=$ polymerase chain reaction; RACE = rapid amplification of cDNA ends; RISC = RNAi-induced silencing complex; RNAi $=$ RNA interference; siRNA = small interfering RNA; SOE = splicing by overlapping extension; stRNA = short temporal RNA; uORF = upstream open reading frame. 
noticed that it is infested with many upstream open reading frames (uORF) and out of frame AUG codons [16]. To evaluate whether the 5 '-untranslated region of the dicer transcript is in part responsible for the regulation of the dicer transcripts in human breast cells we have amplified, cloned and functionally characterized the 5'-leader sequences of human dicer transcripts from these cells. We report here that the dicer gene in breast cells is transcribed from a far upstream promoter in chromosome 14 and the sequence of the 5 '-leader sequences determines the translatability of the dicer transcript and is dictated by alternative splicing of the 5 '-exons.

\section{Materials and methods Cell culture}

We used a series of commercially available human lines of breast cells, including human mammary epithelial (HME) cells (Clonetics, purchased through Fisher Scientific, Pittsburgh, PA, USA), MDA-MB-231, MCF-7, MDA-MB-468, MCF-10A, and BT549. We also used non-breast cells such as HeLa and HepG2. All cells, other than the HME cells, were purchased from American Type Culture Collection (ATCC, Manassas, VA, USA). HMEC cells were grown in medium purchased from Clonetics under their recommended conditions. Human breast carcinoma MDA-MD-231 and MDA-MD- 468 cells were maintained in Leibovitz's L-15 medium supplemented with 1\% antibiotic/antimycotic and 10\% fetal bovine serum. MCF-10A cells were maintained in a 1:1 mixture of Ham's F12 medium, Dulbecco's modified Eagle's medium supplemented with $1 \%$ antibiotic/antimycotic, $0.098 \mathrm{mg} / \mathrm{ml}$ cholera toxin, $0.02 \mu \mathrm{g} / \mu \mathrm{l}$ epidermal growth factor, $0.5 \mu \mathrm{g} / \mathrm{ml}$ hydrocortisone, and $10 \%$ horse donor heard serum. BT-549 cells were maintained following standard ATCC recommended media. All cells were maintained in a humidified $\mathrm{CO} 2(5 \%)$ incubator at $37^{\circ} \mathrm{C}$. Other cells were maintained and grown in ATCC recommended media and conditions $[17,18]$.

\section{5'-RACE}

Complementary DNAs (cDNA) were made from total RNA (5 $\mu \mathrm{g})$ using random primers following standard protocols $[18,19]$. The cDNAs were dC-tailed and the 5 '-ends of the dicer mRNAs were amplified using a dicer gene specific primer (5'-AGTTGACCAAGAACACCG-3'), and the Abridged Anchor Primer (AAP, Invitrogen, Carlsbad, CA, USA) following 5 '-rapid amplification of cDNA ends (RACE) analysis protocols from Invitrogen. Amplicons were re-amplified successively using nested dicer gene specific primers (5'TGACCAAGAACACCGTCC-3', and 5'-AAATGTCTTCCCTGAGCC-3'), and AUAP and UAP, respectively. All PCRs were done using suggested thermocycler conditions of the 5'RACE protocol (Invitrogen). 5'-RACE products were cloned in the pCRII-Topo vector following TOPO-TA cloning protocols (Invitrogen) and the nucleotide sequences of the cloned inserts were determined by automated DNA sequencing [19].

\section{S1-nuclease protection assay}

Oligonucleotides that were biotinylated at the 5'-end (5'CACAGCATGCCCAAGCTT CTGCTCTCAAAATGCTGATTCTAAGTTC-3', and 5'-GCATTTTTGTTCTAGCACAGC TTACCTTCCCACTCGCCTGCGTTTC-3') spanning the exon 2 and exon 3 boundary of the long 5 '-variant and the exon 1 and exon 4 boundary of the short 5 '-variant of the dicer mRNA, respectively, were custom synthesized and gel-purified (Invitrogen). The standard S1-nuclease protection protocol was followed [19] with the following modifications: total cellular RNA $(10 \mu \mathrm{g})$ was co-precipitated with each probe (10 pmol) and hybridized at $65^{\circ} \mathrm{C}$ for $15 \mathrm{~h} . \mathrm{S} 1$-nuclease (Promega, Madison, WI, USA) was used at a concentration of 500 units/ $\mathrm{ml}$ for $90 \mathrm{~min}$ at $37^{\circ} \mathrm{C}$. Products were analyzed in a $15 \%$ TBEurea gel, electrophoretically transferred to Zeta Probe blotting membrane (BioRad, Hercules, CA. USA) and biotinylated protected probes were detected using the North2South HRP Detection protocol (Pierce, Rockford, IL, USA).

\section{5'Leader sequence/Renilla luciferase constructs}

The long and short form dicer 5'-leader sequences were amplified using the forward primer 5'-GCGGAAGTGGGTGTTTGTTATTTCC-3' and the reverse primer 5'GGATCATAAACTTTCGAAGTCATTGCATTTTTGTTCTAGCACAGC-3'. Gene splicing by overlapping extension (SOE) was used to fuse dicer variants to Renilla luciferase that was amplified with forward primer 5'GCTGTGCTAGAACAAAAATGCAATGACTTCGAAAGTTTATGATCC-3' and reverse primer 5'-CTCGAAGCGGCCGCTCTAG-3' [20]. The Renilla luciferase ORF alone was amplified using forward primer 5'-ATGACTTCGAAAGTTTATGATCC-3' and reverse primer 5'-CTCGAAGCGGCCGCTCTAG-3'. SOEing products were then ligated into the pCRII-Topo vector (Invitrogen), digested with EcoRI (Promega) and cloned at the EcoRI site of pcDNA3.1(+) (Invitrogen) and sequenced with T7 primer to determine the orientation of the cloned insert. It is anticipated from the vector information (Invitrogen) that the Renilla luciferase transcript from these constructs will have a 133 nucleotide vector derived sequence before the 5 -leader sequences from the dicer gene at their 5 '-end. Thus, the nucleotide sequence that is common to the control and the experimental transcripts is 5 'TAGAGAACCCACTGCTTACTGGCTTATCGAAATTAATACGACTCACTATAGGGAGACCCAAGCTGGCTAGCGTTTAAACTTAAGCTTGGTACCGAGCTCGG ATCCACTAGTCCAGTGTGGTGGAATTCGGCTT-3'. This sequence does not have any ATG codon.

\section{Transfection and luciferase assay}

Cells were seeded at $80 \%$ confluency in a 24-well plate for 24 $h$ in their growth media before co-transfection with one of the pcDNA3.1(+) test plasmid constructs and pGL3-control plasmid. The latter was used as a transfection normalization control. Plasmids were mixed at $0.5 \mu \mathrm{g}$ per well and transfection was done using the Lipofectamine Plus transfection reagents 
Figure 1

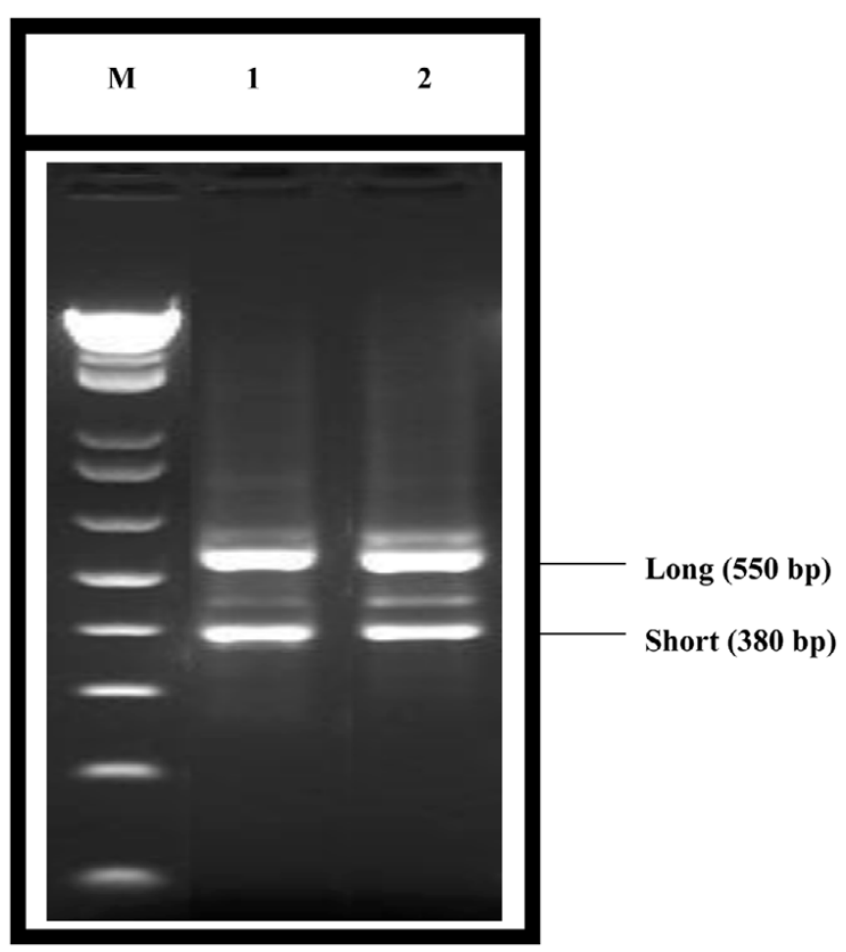

Ethidium bromide stained agarose gel showing the analysis of the 5'RACE products from human dicer mRNAs from breast cells. Lane $\mathrm{M}, 1$ kb plus DNA ladder (Invitrogen); lane 1, cDNA from MDA-MB-231; lane 2 , cDNA from MDA-MB-468. The band at approximately $550 \mathrm{bp}$ is for the unspliced long form of the 5 '-leader sequence. The band at approximately $380 \mathrm{bp}$ is the short spliced form.

(Invitrogen) using the protocol suggested by the supplier. After $20 \mathrm{~h}$ of incubation in complete medium at $37^{\circ} \mathrm{C}$, the cells were lysed in $100 \mu \mathrm{l}$ passive lysis buffer (Promega) and 5-20 $\mu \mathrm{l}$ of the lysate was assayed [18] for firefly luciferase as well as Renilla luciferase activities using Dual Luciferase Assay Reagents (Promega) following suggested protocols [18]. Renilla luciferase activity was normalized with respect to firefly luciferase activity and presented as a ratio (relative light units). Protein contents of the extract, when needed, were determined using RC-DC reagents and protocol from BioRad Laboratories Hercules, CA, USA [18].

\section{In vitro transcription and translation}

The pcDNA3.1(+) constructs containing the cloned inserts also have a T7 RNA polymerase promoter (Invitrogen). To evaluate whether there is any effect of the dicer 5'-leader sequence insert at the EcoRI site in proper orientation on the translatability of the mRNA, we used the T7 RNA polymerase/ rabbit reticulocyte lysate in vitro transcription/translation system (TNT, Promega). Each plasmid DNA $(1 \mu \mathrm{g})$ was added to $40 \mu \mathrm{l}$ of TNT Quick Master Mix containing $1 \mathrm{mM}$ of methionine (Promega). The reactions were incubated at $30^{\circ} \mathrm{C}$ for $75 \mathrm{~min}$ then cooled to $4^{\circ} \mathrm{C}$. The TNT reactions were diluted 1:2 with $1 \mathrm{x}$ passive lysis buffer (Promega) and incubated at room tem-

\section{Figure 2}

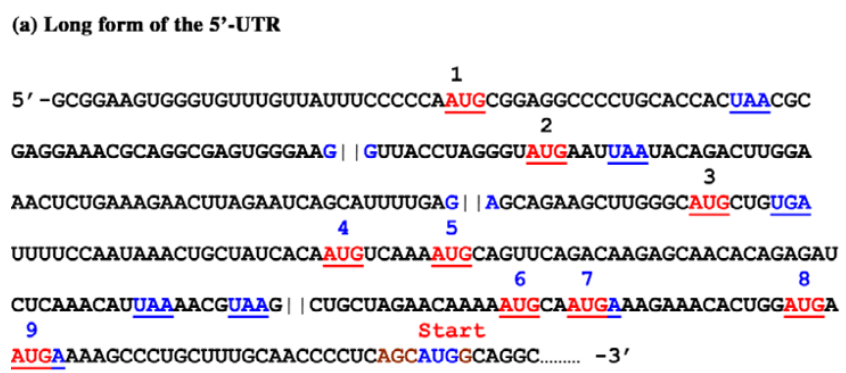

(b) Short form of the 5'-UTR

1

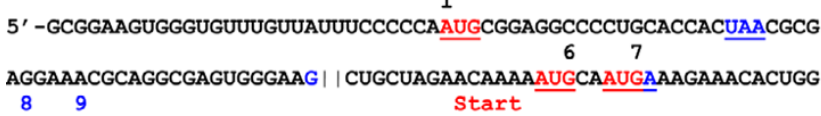
$\begin{array}{cc}8 & 9 \\ \text { AUGAAUGAAAAGCCCUGCUUUGCAACCCCUCAGCAUGGCAGGC.......... } & -3^{\prime}\end{array}$

Nucleotide sequences of the (a) long form and (b) short form of the 5'leaders derived from the 5'-RACE products (Entrez Accession numbers AY845867 and AY845868). The exon junctions are indicated by two vertical lines. The upstream AUGs and corresponding stop codons are numbered and underscored. The AUG at the $3^{\prime}$-end is the putative start codon.

perature for $15 \mathrm{~min}$. An aliquot $(5-20 \mu \mathrm{l})$ was assayed in 100 $\mu \mathrm{l}$ of Renilla Luciferase Assay Substrate (Promega).

\section{Statistical procedures}

Each data set is presented as mean \pm SEM $(N=12)$. Statistical significance of a difference between two series of data was tested by determining the $P$ value [21]. If the $P$ value was less than 0.05 , the difference was considered to be significant [21].

\section{Results and discussion}

\section{Dicer mRNA has a new exon at the 5'-end}

The expression of the dicer gene is differentially regulated in many organisms that have the RNAi mechanism [22-26]. In humans the expression of this gene is highly tissue specific [16] and the mechanisms that regulate it are not known. Initial characterization of dicer mRNA indicated an abundance of overlapping and non-overlapping uORFs at the 5'-leader sequences [16]. To evaluate whether the 5'-leader sequences of dicer mRNA may be a regulatory factor for dicer gene expression, we amplified, cloned and characterized the 5'leader sequences of these mRNAs from human breast cells. We found that dicer mRNAs have at least two major 5'-leader sequences (Figs 1, 2, 3). Fig. 1 shows our 5'-RACE data from MDA-MB-231 and MDA-MB-468 cells. Similar experiments were done with BT549, MCF7, MCF10A and HMEC cells with similar results (not shown). In fact, we also found these two major forms in HepG2 and HeLa cells (data not shown). We purified the PCR products as a whole and cloned all the DNA molecules. Nucleotide sequencing of more than 40 clones revealed only two types of sequences from dicer 
Figure 3

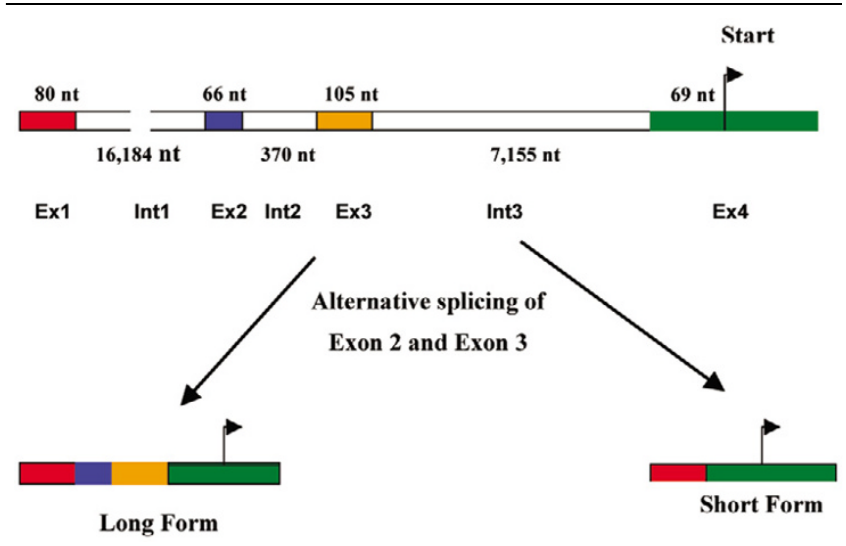

Cartoon showing the possible splicing of the 5 '-exons of the human dicer pre-mRNA to produce the short and long forms of mRNAs.

mRNAs (Fig. 2). The other bands in the 5'-RACE products were thus PCR artifacts deriving from mis-priming. The 5'leader sequences in the characterized dicer mRNAs are termed 'long' (320 nucleotides) and 'short' (149 nucleotides) forms because of their lengths. The human dicer gene was originally cloned from HepG2 cells and was shown to be located on chromosome 14q31 near marker D14S605 [16]. The gene was reported to have 28 exons and 27 introns [16]. Our characterization of the 5 -leader sequences of the dicer mRNA variants from breast cells indicate a new exon at the 5 'end and 30 extra nucleotides added to the original first exon (Figs 1, 2, 3). Alignment of the nucleotide sequence to the chromosome 14 sequence shows that the new exon is transcribed from a segment of the chromosome approximately 16 $\mathrm{kb}$ upstream of the transcription start site previously predicted for human dicer mRNA. Because we have not done extensive studies with different non-breast cell types, we cannot say at this point that the transcript originally reported for HepG2 or other types of cells does not exist. It is possible that human dicer gene is transcribed from different promoters in different tissues. Selection of this alternative promoter in breast cells leads to the formation of a new intron 1 that is 16,184 base pairs in length (Fig. 3). Alternative promoter selection is a known mode of regulation of the expression of mammalian genes [27-29].

The long form of the 5 '-leader sequences contains nine upstream AUG codons (Fig. 2). The short form of the 5'-leader sequence is the alternatively spliced form of the long form. In the short form exon 1 is directly joined to exon 4 and exons 2 and 3 are spliced out (Figs 2 and 3 ); the number of upstream AUG codons is decreased to five due to this alternative splicing (Fig. 2). Upstream AUG codons often are reported to slow down the rate of translation of an mRNA [30-37]. We tested whether the decrease in the upstream AUGs has any effect on the translatability of the dicer mRNAs (see below).
Figure 4

(a) Short form

(b) Long form

(c) $\beta$-Actin
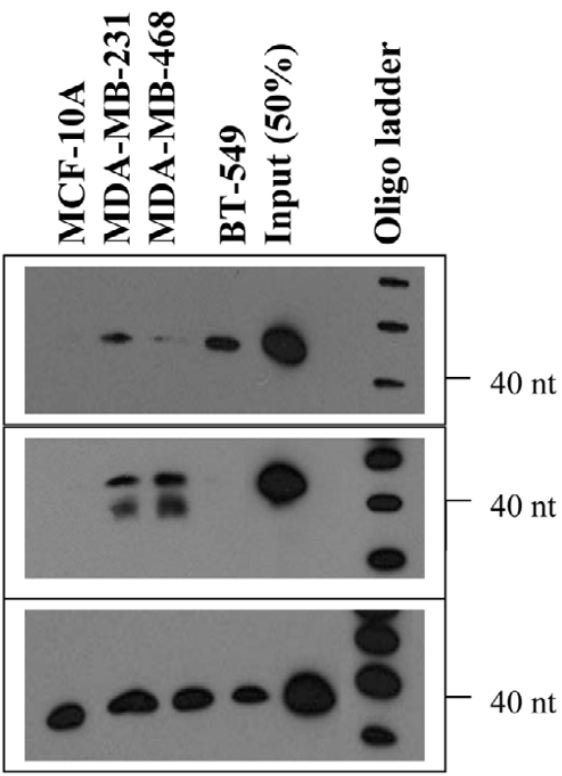

S1-Nuclease protection analysis to verify the long and short forms of dicer mRNA. Autoradiograms showing the relative quantities of (a) short from, (b) long form and (c) $\beta$-actin mRNAs. See text for details. Lanes from left to right: RNA from MCF-10A cells; RNA from MDA-MB231 cells; RNA from MDA-MB-468 cells; RNA from BT-549 cells; $50 \%$ of the probe input; and biotinylated oligonucleotide ladder. The lower band in the long form second and third lane from left may be the 3 '-truncated ( $2 \mathrm{nt}$ ) form of the biotinylated probe due to the possible degradation of the fraying 3 '-end of probe by $\mathrm{S} 1$ nuclease.

To ensure that the existence of the different 5 '-leader sequences in dicer mRNA as revealed by the 5'-RACE analysis was not a PCR artifact, and also to determine relative quantities of each of the mRNA isoforms, we verified the levels of each of the isoforms by S1-nuclease protection assays (Fig. 4). Data from RNAs isolated from MCF-10A, MDA-MB-231, MDA-MB-468 and BT-549 cells are shown in Fig. 4. We used beta-actin RNA level as a loading control. Both the short and long 5'-leader sequence variants were found in these breast cell lines (not shown). The relative amounts of the two forms vary from cell to cell, indicating that alternative splicing of dicer pre-mRNA could be a form of regulation of dicer gene expression.

\section{Translation of the short 5'-leader form of the dicer mRNA is more efficient}

To evaluate whether the altered length of the 5'-leader sequences has any effect on the ability of the mRNA to be translated we tested reporter gene expression from constructs that had either the short or the long 5'-leader sequence (Fig. 5). The data shown are with the control constructs, which have no added 5'-leader sequence. We also performed additional experiments with constructs that have other unrelated DNA segments of similar lengths. We found no significant differences between these controls (data not shown). Transient 


\begin{tabular}{c|c|c|c|}
$\begin{array}{c}133 \mathrm{nt} \\
\text { (V) }\end{array}$ & $\begin{array}{c}\text { 5'-UTR } \\
\text { of dicer }\end{array}$ & $\begin{array}{c}\text { Renilla luciferase ORF } \\
(942 \mathrm{nt})\end{array}$ & $\begin{array}{l}\text { 3'-UTR } \\
160 \mathrm{nt}(\mathrm{V})\end{array}$ \\
\hline & & \\
\hline
\end{tabular}

The map of the putative luciferase mRNA synthesized from the plasmid inside the transfected cells. The 5 '-end $133 \mathrm{nt}$ come from the vector. The lengths of the dicer 5 '-leader sequence vary. The control does not have any insert. The 3 '-untranslated region also comes from the vector. $\mathrm{Nt}$, nucleotides; UTR, untranslated region.

Figure 6
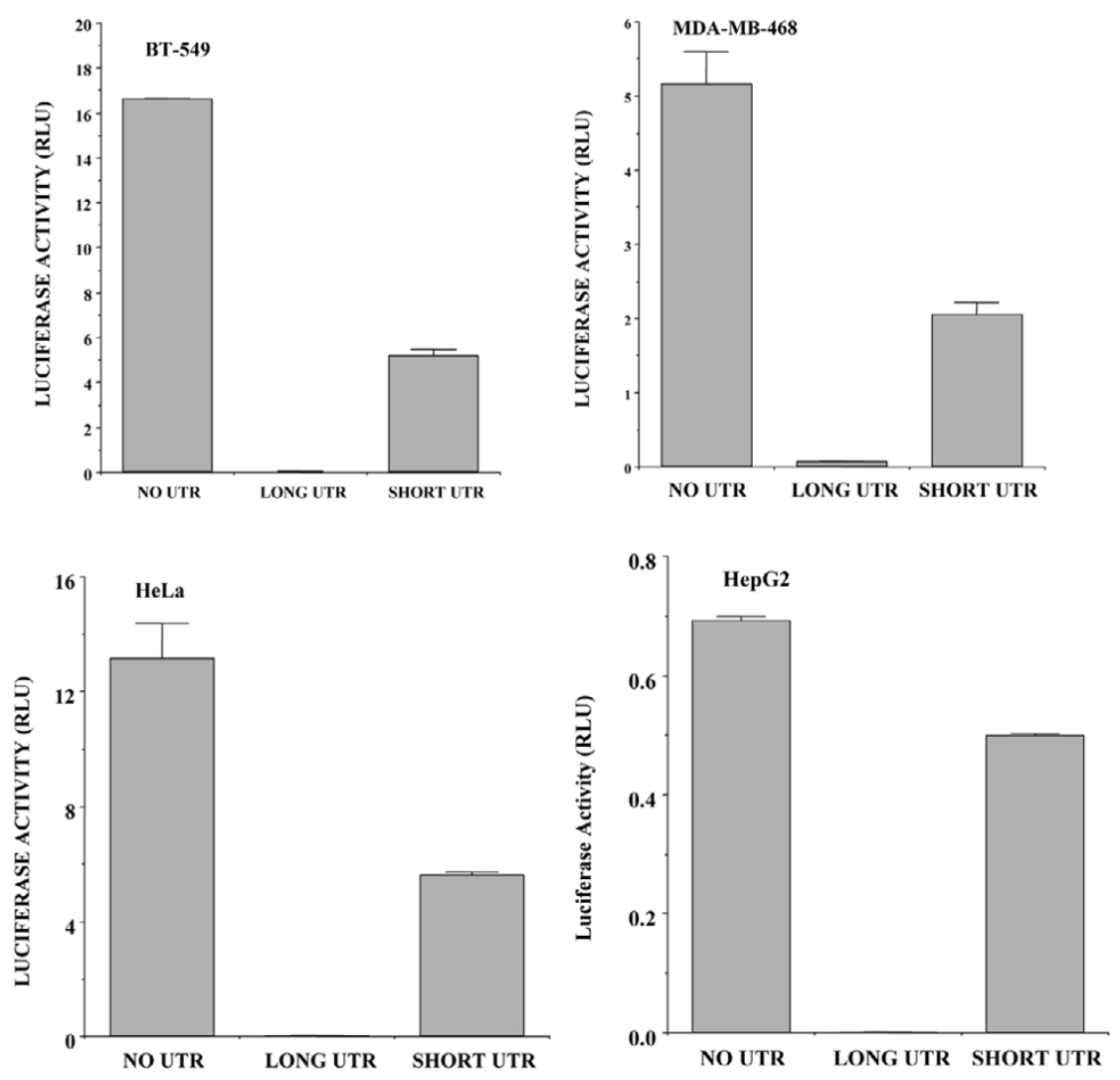

Effect of dicer 5 '-leader sequences upstream of the luciferase coding sequence on the expression of relative luciferase activities in BT549, MDAMB-468, HeLa and HepG2 cells. Luciferase activity is expressed as relative light units (RLU) after normalization with firefly luciferase activity. Results are means of data from 12 different experiments \pm standard errors. The differences were statistically significant $(p<0.001)$. UTR, untranslated region.

transfection of the breast or non-breast cells with the plasmid constructs was supposed to produce Renilla luciferase mRNAs with the general structure shown in Fig. 5 . We lysed the transfected cells after $20 \mathrm{~h}$ and assayed for Renilla luciferase activity in the cell lysate. The plasmid that constitutively expresses firefly luciferase from SV40 late promoter was used as transfection control and the Renilla luciferase data were normalized with respect to the firefly luciferase activity in the extract. Tthe construct with the long form of the 5'-leader sequence expressed no significant Renilla luciferase activity compared to the controls (Fig. 6) in all the cells tested. On the other hand, the construct with the short form of the 5 '-leader sequence expressed significant Renilla luciferase activity (Fig. 6 ). The activity from the construct with the short form of the 5'leader sequence was much less than from the constructs with no added 5'-leader sequence, indicating that the residual AUG codons in the short form of the 5 '-leader sequence may still be negatively regulating the translation and/or stability of the mRNA. To verify whether inclusion of different 5'-leader sequences in the reporter plasmid has any effect on the level of Renilla luciferase mRNA, we performed RT-PCR analysis. Our data suggest that irrespective of whether the construct 
Figure 7

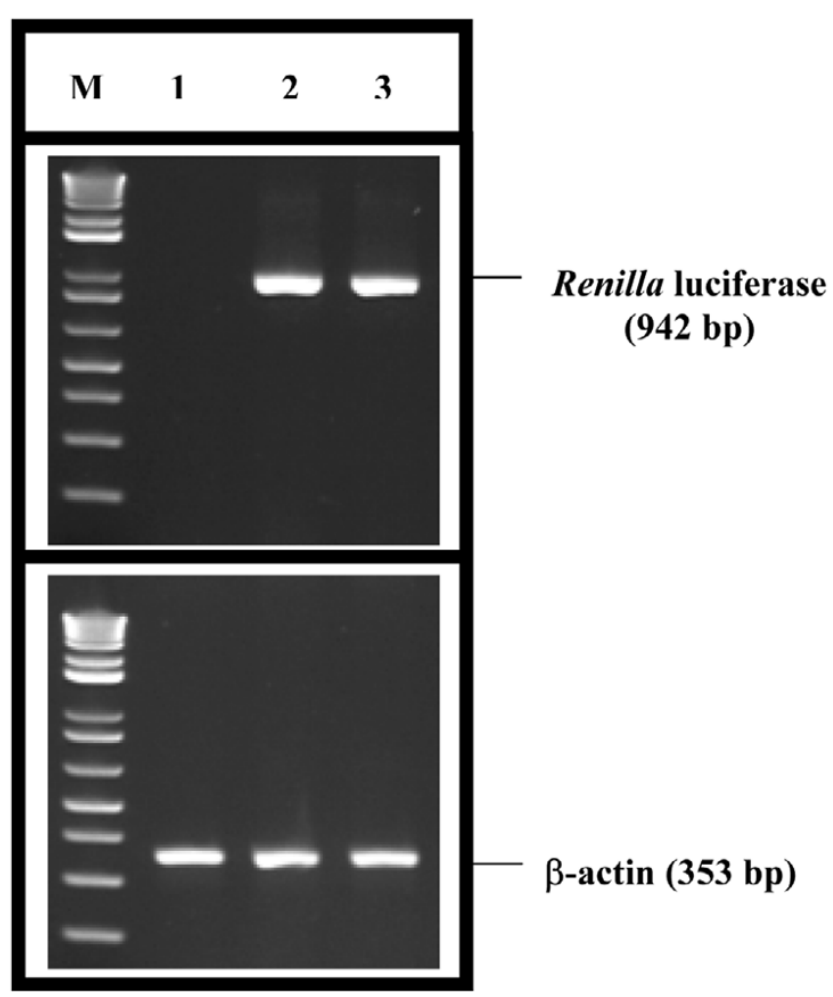

Verification of Renilla luciferase mRNA levels by RT-PCR in transfected BT549 cells. $\beta$-Actin mRNA levels were used as control. Lane M, $1 \mathrm{~kb}$ plus DNA ladder (Invitrogen; lowest band is $200 \mathrm{bp}$ ); lane 1-3, RNA isolated from BT549 cells transfected with pcDNA3.1(+), pcDNA3.1(+)-short form 5'-leader or pcDNA3.1(+)-long form plasmid DNA, respectively.

expresses luciferase activity, there is no significant difference in the luciferase mRNA levels (Fig. 7). The effect of the added 5 '-leader sequences thus may be at the translational level. We further verified this by in vitro transcription/translation with the plasmid constructs followed by reporter gene expression analysis (Fig. 8). This experiment also suggests that perhaps the consequence of altering the 5'-leader sequence of human dicer transcripts is the altered translation of the mRNA into dicer protein. Taken together, these observations imply that alternative promoter use and alternative splicing of 5 '-exons are important for the regulation of human dicer gene expression.

\section{Conclusion}

In human breast cells, the dicer gene is transcribed from a promoter that is more than $16 \mathrm{kbp}$ upstream of the initiation site reported for this gene from non-breast cells [16]. This alternative promoter selection modifies the length and composition of the 5'-leader sequences of its mRNA. Furthermore, alternative splicing of the exon 2 and 3 sequences of its pre-mRNA creates a more translationally competent mRNA in these cells. Breast cell dicer mRNAs have a high number of upstream
Figure 8

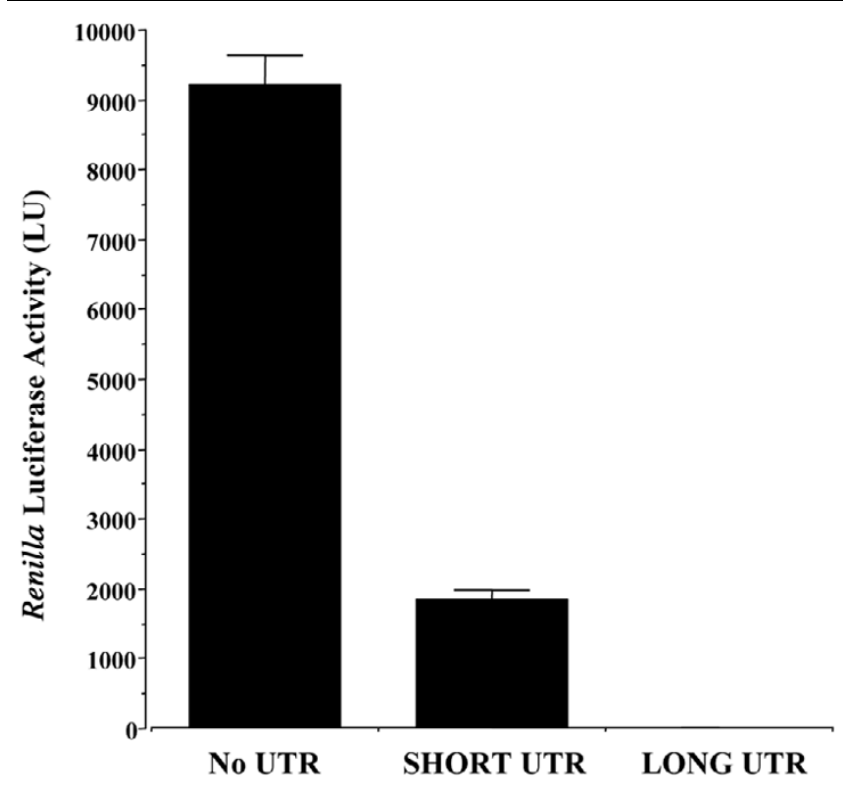

In vitro transcription and translation of the Renilla luciferase gene from the plasmid constructs and evaluation of the luciferase activity. Results are means of data from 12 different experiments \pm standard errors. The differences were statistically significant $(p<0.001)$. UTR, untranslated region.

AUG codons with in frame stop codons. Translational efficiency and/or stability of the RNA are decreased due to this type of 5'-leader sequence [34-37]. The non-sense mediated degradation pathway of mRNA decay may also be stimulated by these uORFs $[38,39]$. It is interesting to note that there is an association between active dicer mRNA expression and the invasiveness of the breast cell line. Recently we found that the zinc finger repressor protein SLUG may have the determinative role in the invasiveness of the breast cell $[40,41]$. We are exploring whether dicer regulates SLUG gene expression in human breast cells. The mechanisms by which the 5 '-leader sequences of the dicer mRNAs in breast cells regulate the expression of this gene are yet to be determined.

\section{Competing interests}

The author(s) declare that they have no competing interests.

\section{Authors' contributions}

CVIW executed the experiments described in the manuscript and wrote the initial drafts of the manuscript. GC conceived and coordinated the study. All authors read and approved the final manuscript.

\section{Acknowledgements}

Supported by the MMC/VICC cancer partnership grant \#1U54CA091408-010003 from NCl and the DOD grant \#DAMD1700-1-0341 to GC and graduate training fellowship \#1T32GM06275801 from $\mathrm{NIH}$ to CVIW. 


\section{References}

1. Campbell TN, Choy FY: RNA interference: past, present and future. Curr Issues Mol Biol 2005, 7:1-6.

2. Nesterova $M$, Cho-Chung YS: Killing the messenger: antisense DNA and siRNA. Curr Drug Targets 2004, 5:683-689.

3. Manoharan M: RNA interference and chemically modified small interfering RNAs. Curr Opin Chem Biol 2004, 8:570-579.

4. Banan M, Puri N: The ins and outs of RNAi in mammalian cells. Curr Pharm Biotechnol 2004, 5:441-450.

5. Silva J, Chang K, Hannon GJ, Rivas FV: RNA-interference-based functional genomics in mammalian cells: reverse genetics coming of age. Oncogene 2004, 23:8401-8409.

6. Stevenson M: Therapeutic potential of RNA interference. N Engl $J$ Med 2004, 351:1772-1777.

7. Lingel A, Izaurralde $E$ : RNAi: finding the elusive endonuclease. RNA 2004, 10:1675-1679.

8. Hannon GJ, Rossi JJ: Unlocking the potential of the human genome with RNA interference. Nature 2004, 431:371-378.

9. Nelson P, Kiriakidou M, Sharma A, Maniataki E, Mourelatos Z: The microRNA world: small is mighty. Trends Biochem Sci 2003, 28:534-540.

10. Tijsterman M, Plasterk RH: Dicers at RISC; the mechanism of RNAi. Cell 2004, 117:1-3.

11. Carmell MA, Hannon GJ: RNase III enzymes and the initiation of gene silencing. Nat Struct Mol Biol 2004, 11:214-218.

12. Kawasaki $\mathrm{H}$, Taira $\mathrm{K}$ : Induction of DNA methylation and gene silencing by short interfering RNAs in human cells. Nature 2004, 431:211-217.

13. Morris KV, Chan SWL, Jacobson SE, Looney DJ: Small-interfering RNA-induced transcriptional gene silencing in human cells. Science 2004, 305:1289-1292.

14. Lippman Z, Martienssen R: The role of RNA interference in heterochromatic silencing. Nature 2004, 431:364-370.

15. Matzke M, Aufsatz W, Kanno T, Daxinger L, Papp I, Mette MF, Matzke AJ: Genetic analysis of RNA-mediated transcriptional gene silencing. Biochim Biophys Acta 2004, 1677:129-141.

16. Matsuda S, Ichigotani Y, Okuda T, Irimura T, Nakatsugawa S, Hamaguchi $M$ : Molecular cloning and characterization of a novel human gene (HERNA) which encodes a putative RNAhelicase. Biochim Biophys Acta 2000, 1490:163-169.

17. Sharan C, Hamilton N, Parl AK, Singh PK, Chaudhuri G: Identification and characterization of a transcriptional silencer upstream of human BRCA2 gene. Biochem Biophys Res Commun 1999, 265:285-290.

18. Tripathi MK, Chaudhuri G: Down-regulation of UCRP and UBE2L6 in BRCA2 Knocked-Down human breast cells. Biochem Biophys Res Commun 2005, 328:43-48.

19. Sambrook J, Russell DW: Molecular Cloning: A Laboratory Manual Cold Spring Harbor Laboratory Press, Cold Spring Harbor, NY; 2001.

20. Dieffenbach CW, Dveksler GS: PCR Primer: A Laboratory Manual Cold Spring Harbor, New York: Cold Spring Harbor Laboratory Press; 1995

21. Campbell MJ, Machin D: Medical Statistics: A Commonsense Approach 2nd edition. New York: John Wiley; 1994.

22. Hammond SM, Bernstein E, Beach D, Hannon GJ: An RNAdirected nuclease mediates post-transcriptional gene silencing in Drosophila cells. Nature 2000, 404:293-296.

23. Liu Q, Rand TA, Kalisas S, Du F, Kim HE, Smith DP, Wang X: R2D2, a bridge between the initiation and effector steps of the Drosophila RNAi pathway. Science 2003, 301:1921-1925.

24. Banerjee D, Slack F: Control of developmental timing by small temporal RNAs: a paradigm for RNA-mediated regulation of gene expression. Bioessays 2002, 24:119-129.

25. Ketting RF, Fischer SE, Berstein E, Sijen T, Hannon GJ, Plasterk $\mathrm{RH}$ : Dicer functions in RNA interference and in synthesis of small RNA involved in developmental timing in C. elegans. Genes Dev 2001, 15:2654-2659.

26. Grishok A, Pasquinelli AE Conte D, LiN Parrish S, Ha I, Baillie DL, Fire A, Ruvkun G, Mello CC: Genes and mechanisms related to RNA interference regulate expression of small temporal RNAs that control C. elegans developmental timing. Cell 2001, 106:23-34

27. Itani OA, Campbell JR, Herrero J, Snyder PM, Thomas CP: Alternate promoters and variable splicing lead to $\mathrm{hNedd4-2}$ iso- forms with a $\mathbf{C 2}$ domain and varying number of WW domains. Am J Physiol Renal Physiol 2003, 285:916-929.

28. Munoz-Sanjuan I, Smallwood PM, Nathans J: Isoform diversity among fibroblast growth factor homologous factors is generated by alternative promoter usage and differential splicing. $J$ Biol Chem 2000, 275:2589-2597.

29. Ball HJ, Shine J, Herzog H: Multiple promoters regulate tissuespecific expression of the human NPY-Y1 receptor gene. J Biol Chem 1995, 270:27272-27276.

30. Jin X, Turcott E, Englehardt S, Mize GJ, Morris DR: The two upstream open reading frames of oncogene $\mathrm{mdm} 2$ have different translational regulatory properties. J Biol Chem 2003, 278:25716-25721.

31. Child SJ, Miller MK, Geballe AP: Translational control by an upstream open reading frame in the HER-2/neu transcript. $J$ Biol Chem 1999, 274:24335-24341.

32. Morris DR, Geballe AP: Upstream open reading frames as regulators of mRNA translation. Mol Cell Biol 2000, 20:8635-8642.

33. Vilela $\mathrm{C}, \mathrm{McC}$ arthy JE: Regulation of fungal gene expression via short open reading frames in the mRNA 5 'untranslated region. Mol Microbiol 2003, 49:859-867.

34. Lu PD, Harding HP, Ron D: Translation reinitiation at alternative open reading frames regulates gene expression in an integrated stress response. J Cell Biol 2004, 167:27-33.

35. Muller EA, Danner DJ: Tissue-specific translation of murine branched-chain alpha-ketoacid dehydrogenase kinase mRNA is dependent upon an upstream open reading frame in the $5^{\prime}$ untranslated region. J Biol Chem 2004, 279:44645-44655.

36. Sapetschnig A, Koch F, Rischitor G, Mennenga T, Suske G: Complexity of translationally controlled transcription factor $\mathrm{Sp3}$ isoform expression. J Biol Chem 2004, 279:42095-42105.

37. Meijer HA, Thomas AA: Control of eukaryotic protein synthesis by upstream open reading frames in the 5 '-untranslated region of an mRNA. Biochem $J 2002,367: 1-11$.

38. Singh G, Lykke-Andersen J: New insights into the formation of active nonsense-mediated decay complexes. Trends Biochem Sci 2003, 28:464-466.

39. Holbrook JA, Neu-Yilik G, Hentze MW, Kulozik AE: Nonsensemediated decay approaches the clinic. Nat Genet 2004, 36:801-808.

40. Tripathi MK, Misra S, Chaudhuri G: Negative regulation of the expressions of cytokeratins 8 and 19 by SLUG repressor protein in human breast cells. Biochem Biophys Res Commun 2005, 329:508-515.

41. Tripathi MK, Misra S, Khedkar SV, Hamilton N, Irvin-Wilson C, Sharan C, Sealy L, Chaudhuri G: Regulation of BRCA2 gene expression by the SLUG repressor protein in human breast cells. $J$ Biol Chem 2005, 280:17163-17171. 